\title{
Azadirachtin-A a bioactive compound from Azadiracta indica is a potential inhibitor of SARS-CoV-2 main protease
}

\section{Dauda Muhammed ${ }^{1}$, Bernard O. Odey², Blessing U. Alozieuwa ${ }^{3}$, Rahmatallah A. Alawode ${ }^{1}$, Banke M. Okunlola ${ }^{4}$, Jonathan Ibrahim ${ }^{5}$, Abdullateef Lawal' ${ }^{6}$, Eustace B. Berinyuy ${ }^{7 *}$}

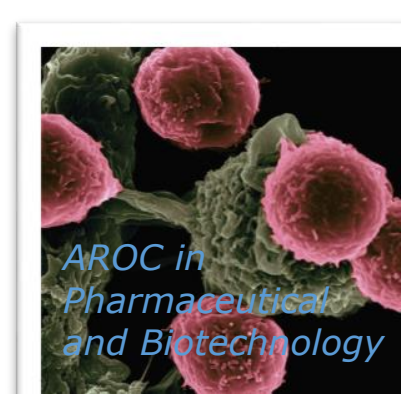

${ }^{1}$ Southern Guinea Research Station-Forestry Research Institute of Nigeria, Nigeria

${ }^{2}$ Trial Afforestation Research Station-Forestry Research Institute of Nigeria, Afaka, Kaduna State, Nigeria

${ }^{3}$ Department of Biochemistry, Veritas University Abuja, Bwari, FCT-Abuja, Nigeria

${ }^{4}$ Department of Microbiology, Federal University of Technology Minna, Nigeria

${ }^{5}$ Gombe State College of Health Science and Technology, Kaltungo, Nigeria

${ }^{6}$ Department of Chemistry, University of Ilorin, Ilorin, Nigeria

${ }^{7 *}$ Faculty of Medicine and Biomedical Science, University of Yaoundé I, Yaounde, Cameroon

Despite the growing scientific interest in finding effective treatment, SARS-CoV-2 virus remains a global major health burden and public health emergency. SARS-CoV main protease (Mpro) also known as chymotrypsin-like protease (3CLpro) is an important protein identified to be vital for SARS-CoV-2 survival. However, to date, there are no clinically approved drugs or antibodies specific for SARS-CoV-2. In the present study, we evaluated the interaction of 3CLpro with azadirachtin-A a bioactive compound from Azadiracta indica using in silico molecular docking study. Our results revealed that Azadiractin A docked well into the binding cavity of 3CLproSARS-CoV-2 with binding affinities ranges between -6.3 and $-5.20 \mathrm{kcal} / \mathrm{mol}$, and Pkd of $5.82 \sim 6.10$ for the ten best binding modes. Azadiractin interacted with the active site of 3CLpro-SARS-CoV-2 by 2 conventional hydrogen bonding to HIS163 and GLU166, C-H interactions with HIS127, and alkyl interaction with PRO168 of the 3CLpro-SARS-CoV-2. We also found that the Azadiractin-A_3CLpro-SARS-CoV-2 complex is stabilized by various Vander wall forces with ASN142, LEU141, PHE140, MET165, GLN189, LEU167, THR190, and ALA191. In conclusion, our results suggested that Azadirachtin-A could be a potential inhibitor of SARS-CoV-2 main protease, thus worthy of further preclinical study.

Keywords: Azadirachtin-A; Azadiracta indica; SARS-CoV-2 main protease; molecular docking

Received: 19 April 2021, Revised: 20 May 2021, Published: 24 May 2021;

Citation: Muhammed, D., Odey, B.O., Alozieuwa, B.U., Alawode, R.A., Okunlola, B.M., Ibrahim, J., Lawal, A., Berinyuy E.B. (2021). Azadirachtin-A a bioactive compound from Azadiracta indica is a potential inhibitor of SARS-CoV-2 main protease. AROC in Pharmaceutical and Biotechnology, 1(1):01-08

\subsection{Introduction}

Coronaviruses are enveloped non-segmented positive-sense RNA viruses belonging to the order Nidovirales and Coronaviridae family widely distributed in humans and other mammals [1]. Generally, coronaviruses (CoVs) are categorized into four major genera including Betacoronavirus, Alphacoronavirus, Deltacoronavirus, and Gammacoronavirus [2]. In humans, CoVs usually cause mild to moderate upper-respiratory-tract infection, such as the common cold, however, the rarer forms of CoVs can be lethal. In December
2019, a series of pneumonia cases of unknown cause emerged in Wuhan, Hubei, China, with clinical presentations greatly resembling viral pneumonia [3]. However, recently, six groups of human CoV have been reported including HCoV-229E and HCoV-NL63 belonging to Alphacoronavirus genera, severe acute respiratory syndrome SARS-CoV, HCoVHKU1, HCoV-OC43, and Middle East respiratory syndrome MERS-CoV, belonging to genera of Betacoronavirus [4]. However, of the six CoVs, SARS-CoV, and MERS-CoV, are the most infective and lethal and are associated with the 
outbreak of two epidemics at the beginning of the 21st century [5] .

There is a rapid ongoing search for therapeutics against SARS-CoV-2 [6]. Drugs targeting either the $\mathrm{S}$ protein or main protease have been screened. These approaches have led to the discovery of small molecules with high binding affinities to the aforementioned proteins [7]. SARS-CoV main protease (Mpro) also known as chymotrypsin-like protease (3CLpro). Mpro cleaves most of the sites in the polyproteins and the products are nonstructural proteins (nsps) which assemble into the replicase-transcriptase complex (RTC). However, to date, there are no clinically approved drugs or antibodies specific for SARS-CoV-2.

African natural products are generally known to be therapeutically effective in the management of diseases including parasitic, antiviral, antimicrobial, anticancer, antioxidants, and several other diseases [8-11]. In addition, natural products are bio-friendly and exhibited no or minimal side effects as compared to conventional therapies [12-14]. Azadirachta indica A. Juss is a medicinal plant commonly known as neem, has been extensively used in Ayurvedic medicine by the Nigerian population for treatments of several diseases including virus infections. It has been scientifically reported for anti-viral activity against several serotypes of coxsackievirus B [15], poliovirus [16], dengue virus type 2 [17] showed the inhibitory effect of neem leaves aqueous extract on dengue virus and HSV-1 virus [18], BoHV-1[19]. The traditional use as antiviral is described for the treatment of animals suffering from bovine and avian poxvirus infections by applying a paste of neem leaves directly on the infected skin [20]. In addition, Neem is considered harmless to animals, insects, humans, birds, and earthworms and has also been approved by the United States Environmental Protection Agency for use as a food crop [21].

Major chemical constituents of neem are terpenes and limonoids. The major active components in the limonoids are azadirachtin, 3-deacetyl-3cinnamoylazadirachtin, 1-tygloyl-3-acetyl-2methoxyazadirachtin, 22,23-dihydro-23ßmethoxyazadirachtin, nimbanal, 3tigloylazadirachtol, 3-acetyl-salannoV nimbidioV margocin, margocinin, margocilin, and others [21]. Azadirachtin $A$ is a member of the family of azadirachtins. Structurally, azadirachtin is an organic heterotetracyclic compound, an epoxide, an enoate ester, an acetate ester, methyl ester, a cyclic hemiketal, and tertiary alcohol.

The process of drug discovery and development entails series of stages that include target identification and validation, lead identification, optimization, pre-clinical evaluation of pharmacology and toxicology, and clinical studies $[22,23]$. Today in silico drug target identification has become an essential tool in drug discovery and development and has been widely employed in identifying a reliable target in preclinical and clinical settings [24-26].

The availability of crystalized protein structure, ligands structures, and ligand database made it easier to simulate the possible interactions of drug candidates with potential targets and hence enable the identification of therapeutic implications and possible biological processes regulated by the drug candidate. In the present study, we demonstrate the drug-likeness and structural based evidence for its potential to be a novel SARS-CoV-2 inhibitor via targeting the main protease (Mpro) of the virus.

\section{Material and methods}

\subsection{Source of Azadiractin A with SARS-CoV-2 main protease structure}

The three-dimensional (3D) structure of Azadiractin A, a bioactive compound from Azadiracta indica (Compound CID: 5281303) and the canonical smiles of Azadiractin A $\quad(\mathrm{CC}=\mathrm{C}(\mathrm{C}) \mathrm{C}(=\mathrm{O})$ OC1CC(C2) COC3C2C14COC(C4C(C3O)(C)C56C7CC $(\mathrm{C} 5(\mathrm{O} 6) \mathrm{C})$

$\mathrm{C} 8(\mathrm{C}=\mathrm{COC} 8 \mathrm{O} 7) \mathrm{O})(\mathrm{C}(=0) \mathrm{OC}) \mathrm{O}) \mathrm{C}(=0) \mathrm{OC}) \mathrm{OC}(=0) \mathrm{C}$ ) were obtained from PubChem (https://pubchem.ncbi.nlm.nih.gov). The PDB file formats of the crystal structure of Mpro (PDB; 6LU7) was downloaded from the PDB database (https://www.rcsb.org/).

\subsection{In-silico Pharmacokinetics and Drug- likeness Analysis}

The Pharmacokinetics, drug-likeness, and ADMET properties of Azadiractin A were evaluated using the SwissADME algorithm. The canonical smiles of Azadiractin A were used as a query ID on the SwissADME algorithm. 


\section{3 molecular docking analyses of Azadiractin A with SARS-CoV-2 main protease.}

For molecular docking, the three-dimensional (3D) structure of Azadiractin A (Compound CID: 5281303) was retrieved in SDF file format from the PubChem database and were subsequently transformed into the protein data bank (PDB) format using the PyMOL Molecular Graphics System. The PDB file formats of the crystal structure of Mpro (PDB; 6LU7)was downloaded from the PDB database (https://www.rcsb.org/). The Azadiractin $A$ and and the receptor were subsequently converted into the Auto Dock Pdbqt format using AutoDock Vina [27].

Pre-docking preparation of the receptors followed the removal of water molecules, while hydrogen atoms and Kolmman charges were added accordingly. Molecular docking studies were performed using Autodock VINA software and by following the protocols described in our previous study [24,28]. PyMOL software was used to visualize $\mathrm{H}$-bond interactions, binding affinities, interacting amino acid residues, binding atoms on the ligands and receptors, and 3D graphical representations of ligand-receptor complexes, while 2D graphical illustrations of ligand-binding interactions were further visualized using Discovery studio visualizer [29].

\subsection{Results and Discussion}

The chemical structure of Azadiractin $A$ is shown in Figure $1 \mathrm{~A}$. The six physicochemical properties displayed by the bioavailability radar indicated that Azadiractin A exhibited good physicochemical properties (Figure 1B). However, physicochemical analysis of Azadiractin A revealed low passive gastrointestinal absorption (GIA) and brain permeability (Figure $1 \mathrm{C}$ ). The in silico Pharmacokinetics, drug likeness and ADMET properties of Azadiractin A is shown in table 1.
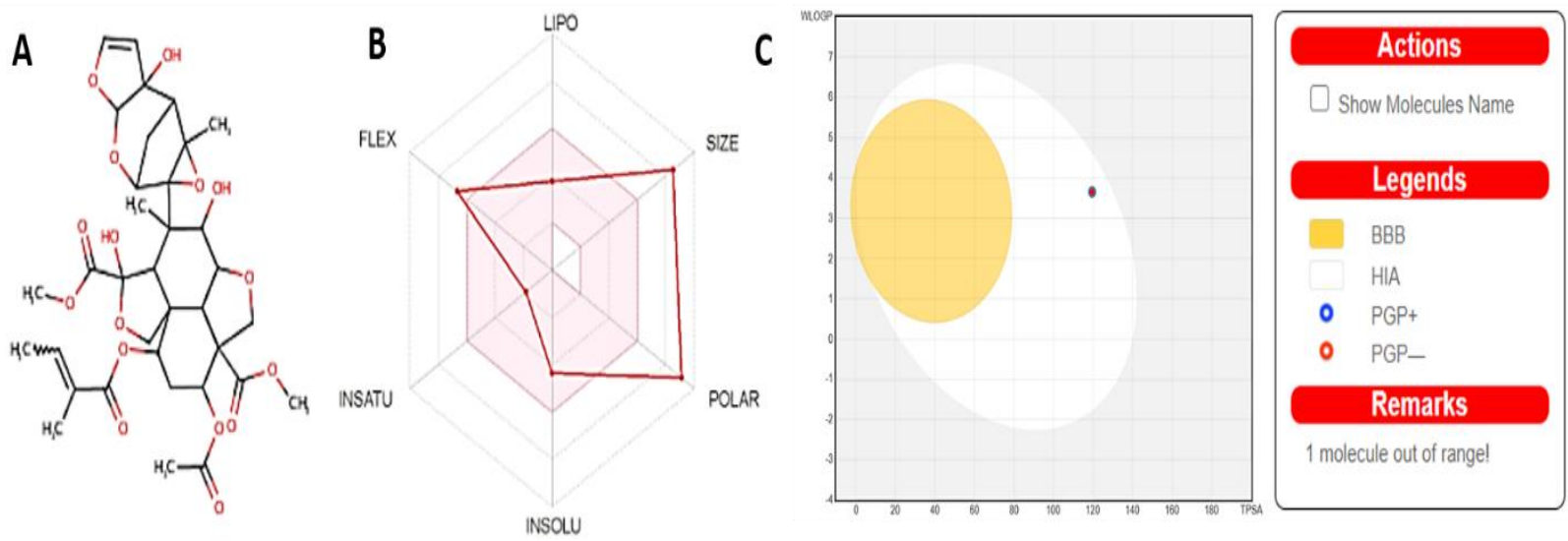

Figure 1: Azadiractin-A (A) Chemical Structure, (B) bioavailability radar and Boiled egg model for blood brain barrier permeation and intestinal absorption property of Azadiractin A. 


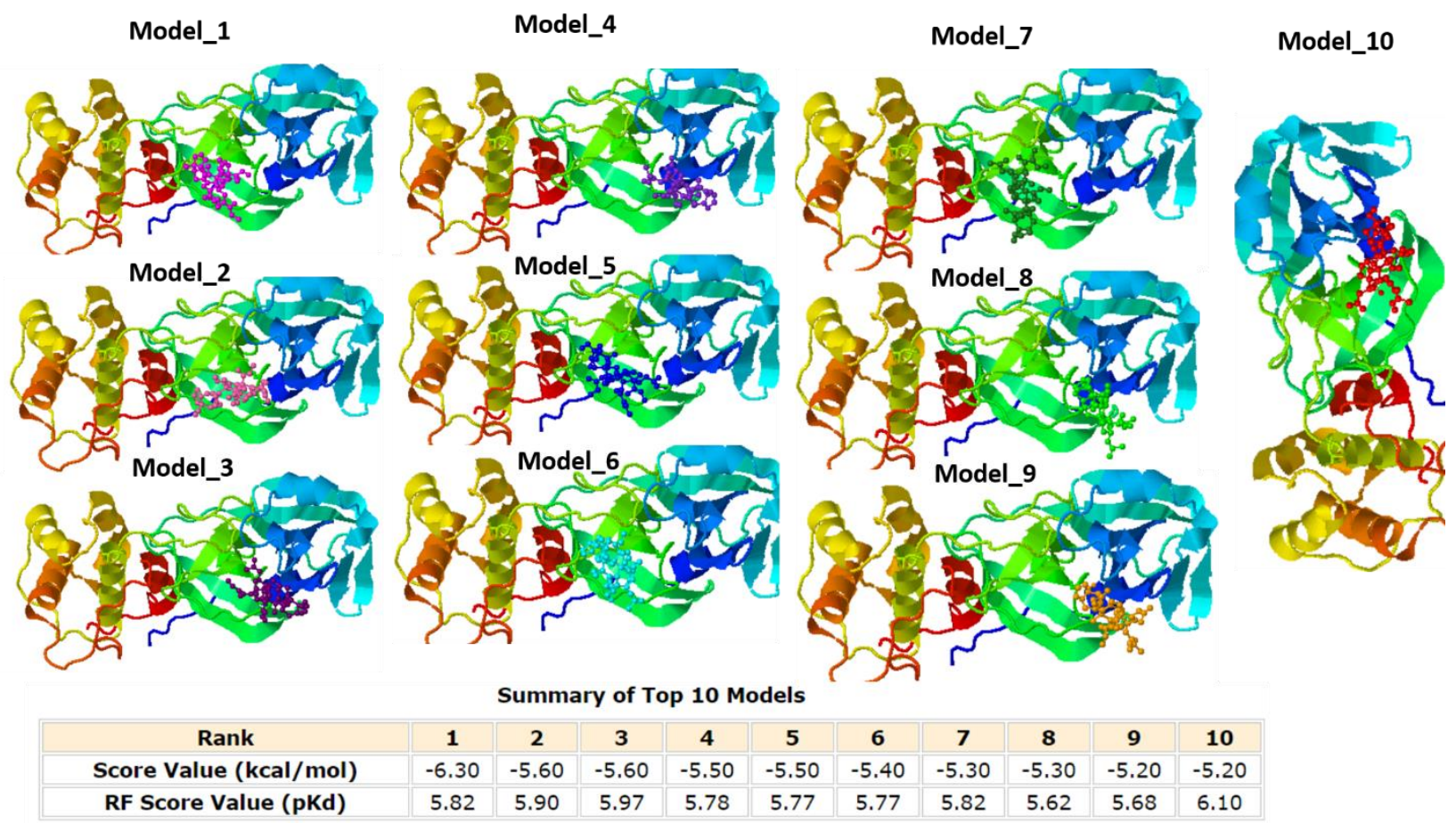

Figure 2: The top ten (10) binding affinities and models of Azadiractin interactions with chymotrypsin-like protease (3CLpro) of covid 19

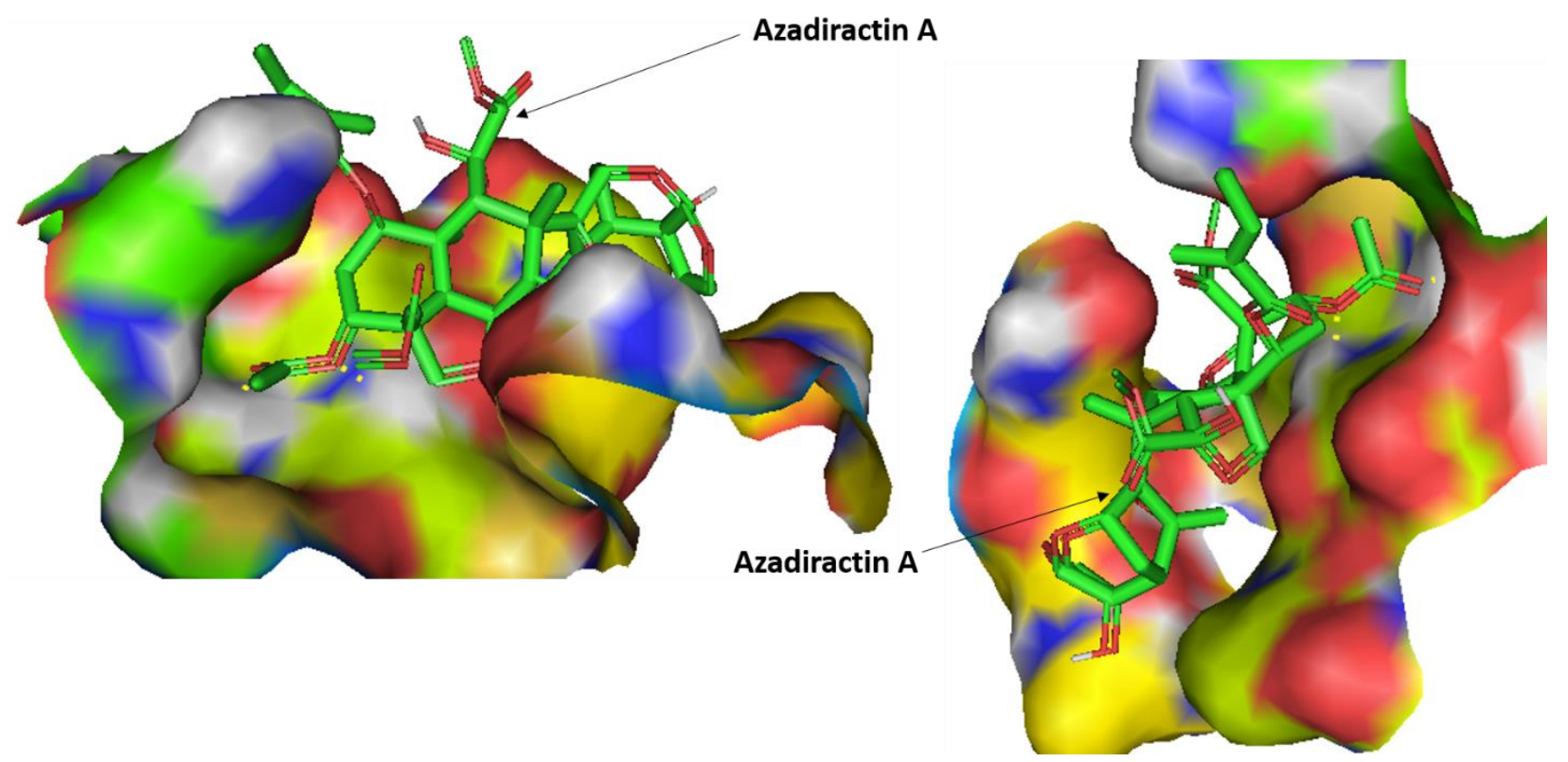

Figure 3: The three dimensional solid srurface representation of Azadiractin $A$ in the binding pocket of the receptor (3CLpro-SARS-CoV-2) 


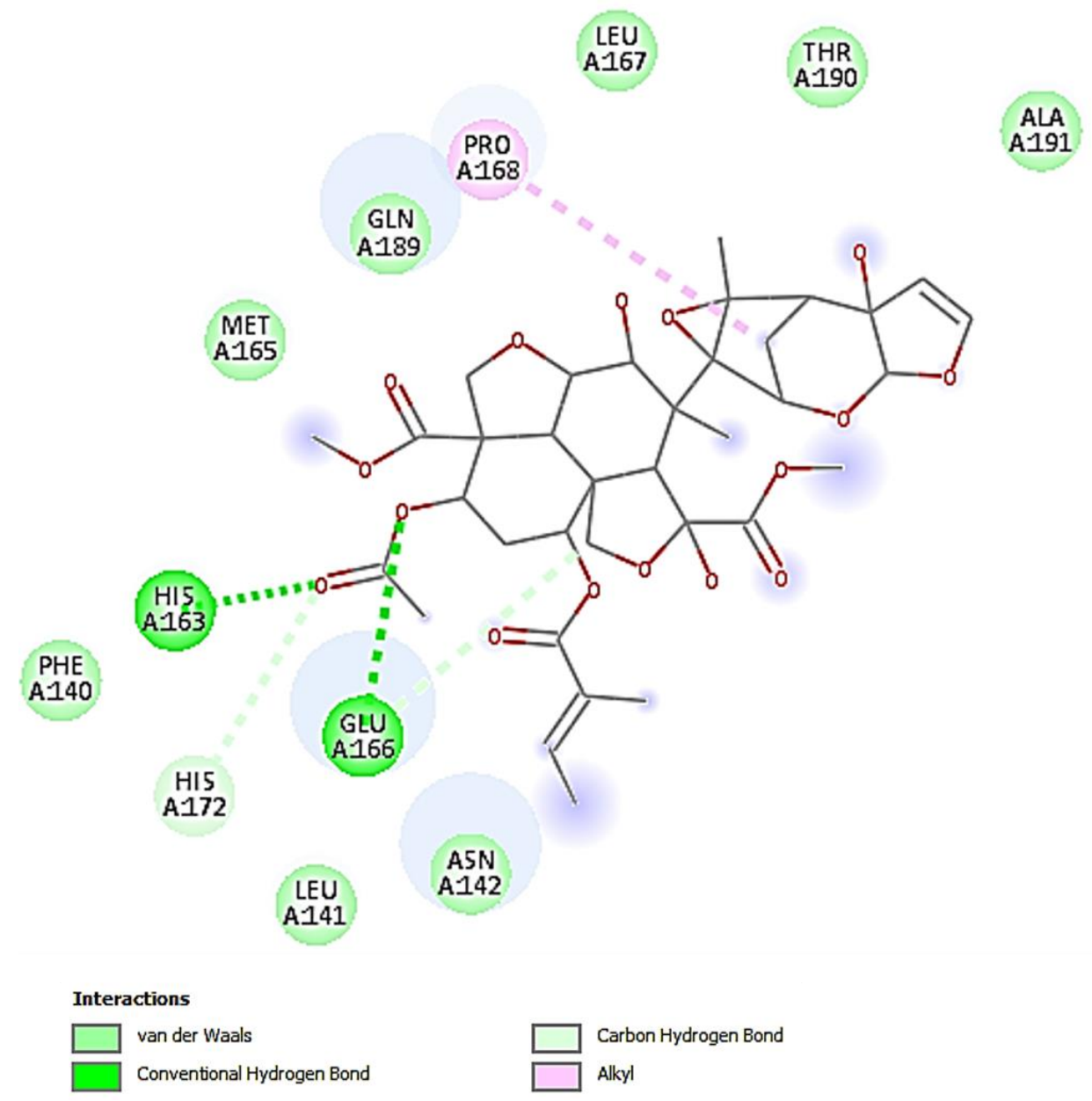

Figure 4: The two dimensional representation of ligand-receptor interaction of Azadiractin-A_3CLpro-SARSCoV-2 complex showing the amino acid interaction in the active site of the 3CLpro-SARS-CoV-2.

Receptor-ligand interactions play useful roles in structure-based drug discovery and development. We analyzed protein-ligand binding complex interactions of Azadiractin A with 3CLpro-SARSCoV-2 using molecular docking studies. Interestingly, we found that Azadiractin A interacted with 3CLpro-SARS-CoV-2 with binding affinities ranges between -6.3 and $-5.20 \mathrm{kcal} / \mathrm{mol}$, and Pkd of $5.82 \sim 6.10$ for the ten best binding mode (Figure 2).
We found that Azadiractin A docked well into the binding cavity of 3CLpro-SARS-CoV-2 (Figure 3 ) by 2 conventional hydrogen bonding to HIS163 and GLU166, C-H interactions with HIS127 and alkyl interaction with PRO168 of the 3CLpro-SARS-CoV2. We also found that the Azadiractin-A_3CLproSARS-CoV-2 complex is stabilized by various Vander wall forces with ASN142, LEU141, PHE140, MET165, GLN189, LEU167, THR190 and ALA191

Table 1: In silico Pharmacokinetics, drug likeness and ADMET properties of Azadiractin A.

Citation: Muhammed, D., Odey, B.O., Alozieuwa, B.U., Alawode, R.A., Okunlola, B.M., Ibrahim, J., Lawal, A., Berinyuy E.B. (2021). Azadirachtin-A a bioactive compound from Azadiracta indica is a potential inhibitor of SARS-CoV-2 main protease. AROC in Pharmaceutical and Biotechnology, 1(1):01- 08 


\begin{tabular}{|l|l|}
\hline Parameters & \multicolumn{2}{l|}{ Values } \\
\hline Physicochemical Properties \\
\hline Formula & C35H44O16 \\
\hline Molecular weight & $720.71 \mathrm{~g} / \mathrm{mol}$ \\
\hline Num. heavy atoms & 51 \\
\hline Num. arom. heavy atoms & 0 \\
\hline Fraction Csp3 & 0.77 \\
\hline Num. rotatable bonds & 10 \\
\hline Num. H-bond acceptors & 16 \\
\hline Num. H-bond donors & 3 \\
\hline Molar Refractivity & 165.92 \\
\hline TPSA & $215.34 \AA^{2}$ \\
\hline Lipophilicity & \\
\hline Log Po/w (iLOGP) & 3.9 \\
\hline Log Po/w (XLOGP3) & 1.09 \\
\hline Log Po/w (WLOGP) & -0.2 \\
\hline
\end{tabular}

The unique stability of Azadiractin $A$ in the binding site of the 3CLpro-SARS-CoV-2 could be attributed to the $\mathrm{H}$-bond and. The high affinity of Azadiractin A was also associated with the presence of larger number of Van der waal forces created on it backbone the respective amino acids ASN142, LEU141， PHE140, MET165, GLN189, LEU167, THR190 and ALA191 which undoubtedly created a strong cohesive environment, thereby stabilizing the complex formed [30]. These high number of interactions undoubtedly contributed to high affinity that Azadiractin A has for 3CLpro-SARS-CoV-2.

\subsection{Conclusion}

In conclusion, our results suggested that Azadirachtin-A demonstrated a robust interaction with the main protease of SARS-CoV-2 and thus could be consider as a potential inhibitor of SARSCoV-2 main protease, worthy of further preclinical study

Author Contributions: The work was conducted in collaboration of all authors. All authors have read and agreed to the published version of the manuscript.

Funding: This work received no external funding

Institutional Review Board Statement: Not Applicable.

Informed Consent Statement: Not Applicable.

\begin{tabular}{|c|c|}
\hline Log Po/w (MLOGP) & -0.47 \\
\hline Log Po/w (SILICOS-IT) & 1.07 \\
\hline Consensus Log Po/w & 1.08 \\
\hline \multicolumn{2}{|l|}{ Water Solubility } \\
\hline Log S (ESOL) & -4.34 \\
\hline Solubility & $\begin{array}{l}3.33 \mathrm{e}-02 \mathrm{mg} / \mathrm{ml} ; 4.62 \mathrm{e}- \\
05 \mathrm{~mol} / / \mathrm{l}\end{array}$ \\
\hline Class & Moderately soluble \\
\hline \multicolumn{2}{|l|}{ Pharmacokinetics } \\
\hline GI absorption & Low \\
\hline BBB permeant & No \\
\hline P-gp substrate & Yes \\
\hline CYP1A2 inhibitor & No \\
\hline CYP2C19 inhibitor & No \\
\hline CYP2C9 inhibitor & No \\
\hline Log Kp (skin permeation) & $-9.92 \mathrm{~cm} / \mathrm{s}$ \\
\hline
\end{tabular}

Acknowledgments: Not Applicable

Conflicts of Interest: The authors declare that no conflict of interest exists.

\section{References}

1. Richman, D.D.; Whitley, R.J.; Hayden, F.G. Clinical virology; John Wiley \& Sons: 2020.

2. Woo, P.C.; Huang, Y.; Lau, S.K.; Yuen, K.Y. Coronavirus genomics and bioinformatics analysis. Viruses 2010, 2, 1804-1820, doi:10.3390/v2081803.

3. Huang, C.; Wang, Y.; Li, X.; Ren, L.; Zhao, J.; Hu, Y.; Zhang, L.; Fan, G.; Xu, J.; Gu, X., et al. Clinical features of patients infected with 2019 novel coronavirus in Wuhan, China. Lancet (London, England) 2020, 395, 497506, doi:10.1016/S0140-6736(20)30183-5.

4. Tang, Q.; Song, Y.; Shi, M.; Cheng, Y.; Zhang, W.; Xia, X.-Q. Inferring the hosts of coronavirus using dual statistical models based on nucleotide composition. Scientific Reports 2015, 5, 17155, doi:10.1038/srep17155.

5. Fehr, A.R.; Perlman, S. Coronaviruses: an overview of their replication and pathogenesis. Methods in molecular biology 
(Clifton, N.J.) 2015, 1282, 1-23, doi:10.1007/978-1-4939-2438-7_1.

6. Jaiswal, G.; Kumar, V. In-silico design of a potential inhibitor of SARS-CoV-2 S protein. PLoS One 2020, 15, e0240004, doi:10.1371/journal.pone.0240004.

7. Bacha, U.; Barrila, J.; Velazquez-Campoy, A.; Leavitt, S.A.; Freire, E. Identification of Novel Inhibitors of the SARS Coronavirus Main Protease 3CLpro. Biochemistry 2004, 43, 4906-4912, doi:10.1021/bi0361766.

8. Lawal, B.; Shittu, O.K.; Kabiru, A.Y.; Jigam, A.A.; Umar, M.B.; Berinyuy, E.B.; Alozieuwa, B.U. Potential antimalarials from African natural products: A reviw. J Intercult Ethnopharmacol 2015, 4, 318-343, doi:10.5455/jice.20150928102856.

9. Lawal, B.; Shittu, O.K.; Oibiokpa, F.I.; Berinyuy, E.B.; Mohammed, H. African natural products with potential antioxidants and hepatoprotectives properties: a review. Clinical Phytoscience 2016, 2, 23, doi:10.1186/s40816-016-0037-0.

10. Adesina, D.A.; Adefolalu, S.F.; Jigam, A.A.; Lawal, B. Antiplasmodial effect and subacute toxicity of alkaloid, flavonoid and phenolic extracts of Sida acuta leaf on Plasmodium berghei-infected animals. Journal of Taibah University for Science 2020, 14, 943-953, doi:10.1080/16583655.2020.1790912.

11. Ibrahim, J.; Kabiru, A.Y.; AbdulrasheedAdeleke, T.; Lawal, B.; Adewuyi, A.H. Antioxidant and hepatoprotective potentials of curcuminoid isolates from turmeric (Curcuma longa) rhizome on $\mathrm{CCl} 4$-induced hepatic damage in Wistar rats. Journal of Taibah University for Science 2020, 14, 908915, doi:10.1080/16583655.2020.1790928.

12. Yusuf, A.A.; Lawal, B.; Yusuf, M.A.; Adejoke, A.O.; Raji, F.H.; Wenawo, D.L. Free radical scavenging, antimicrobial activities and effect of sub-acute exposure to Nigerian Xylopia Aethiopica seed extract on liver and kidney functional indices of albino rat. Iranian journal of toxicology 2018, 12, 51-58.
13. Umar, S.I.; Lawal, B.; Mohammed, B.A.; Obiekezie, C.I.; Adewuyi, A.H.; Babalola, S.B.; Ariyeloye, S.D. Antioxidant and antimicrobial activities of naturally occurring flavonoids from $M$. heterophylla and the safety evaluation in Wistar rats. Iranian Journal of Toxicology 2019, 13, 39-44.

14. Lawal, B.; Shittu, O.K.; Ossai, P.C.; Abubakar, A.N.; Ibrahim, A.M. Evaluation of antioxidant activity of giant African snail (Achachatina maginata) haemolymph in CCl4-induced hepatotoxixity in albino rats. Journal of Pharmaceutical Research International 2015, 141-154.

15. Badam, L.; Joshi, S.P.; Bedekar, S.S. 'In vitro' antiviral activity of neem (Azadirachta indica. A. Juss) leaf extract against group B coxsackieviruses. J Commun Dis 1999, 31, 79-90.

16. SaiRam, M.; Ilavazhagan, G.; Sharma, S.K.; Dhanraj, S.A.; Suresh, B.; Parida, M.M.; Jana, A.M.; Devendra, K.; Selvamurthy, W. Antimicrobial activity of a new vaginal contraceptive NIM-76 from neem oil (Azadirachta indica). Journal of Ethnopharmacology 2000, 71, 377-382, doi:https://doi.org/10.1016/S03788741(99)00211-1.

17. Parida, M.M.; Upadhyay, C.; Pandya, G.; Jana, A.M. Inhibitory potential of neem (Azadirachta indica Juss) leaves on Dengue virus type-2 replication. Journal of Ethnopharmacology 2002, 79, 273-278, doi:https://doi.org/10.1016/S03788741(01)00395-6.

18. Faccin-Galhardi, L.C.; Aimi Yamamoto, K.; Ray, S.; Ray, B.; Carvalho Linhares, R.E.; Nozawa, C. The in vitro antiviral property of Azadirachta indica polysaccharides for poliovirus. Journal of Ethnopharmacology 2012, 142, 86-90, doi:https://doi.org/10.1016/i.jep.2012.04.0 $\underline{18}$.

19. Saha, S.; Galhardi, L.C.F.; Yamamoto, K.A.; Linhares, R.E.C.; Bandyopadhyay, S.S.; Sinha, S.; Nozawa, C.; Ray, B. Water-extracted 
polysaccharides from Azadirachta indica leaves: Structural features, chemical modification and anti-bovine herpesvirus type 1 (BoHV-1) activity. International Journal of Biological Macromolecules 2010, 47 , 640-645, doi:https://doi.org/10.1016/i.ijbiomac.2010 .08 .011$.

20. Biswas, K.; Chattopadhyay, I.; Banerjee, R.K.; Bandyopadhyay, U. Biological activities and medicinal properties of neem (Azadirachta indica). Current Science 2002, 82, 13361345.

21. Kumar, R.; Mehta, S.; Pathak, S.R. Chapter 4 - Bioactive constituents of neem. In Synthesis of Medicinal Agents from Plants, Tewari, A., Tiwari, S., Eds. Elsevier: 2018; https://doi.org/10.1016/B978-0-08-1020715.00004-0pp. 75-103.

22. Lawal, B.; Lee, C.-Y.; Mokgautsi, N.; Sumitra, M.R.; Khedkar, H.; Wu, A.T.H.; Huang, H.-S. mTOR/EGFR/iNOS/MAP2K1/FGFR/TGFB1

Are Druggable Candidates for $\mathrm{N}-(2,4-$ Difluorophenyl)-2',4'-Difluoro-4-

Hydroxybiphenyl-3-Carboxamide (NSC765598), With Consequent Anticancer Implications. Frontiers in Oncology 2021, 11, doi:10.3389/fonc.2021.656738.

23. Lawal, B.; Lin, L.-C.; Lee, J.-C.; Chen, J.-H.; Bekaii-Saab, T.S.; Wu, A.T.H.; Ho, C.-L. MultiOmics Data Analysis of Gene Expressions and Alterations, Cancer-Associated Fibroblast and Immune Infiltrations, Reveals the OncoImmune Prognostic Relevance of STAT3/CDK2/4/6 in Human Malignancies. Cancers (Basel) 2021, 13, 954.

24. Lee, J.-C.; Wu, A.T.H.; Chen, J.-H.; Huang, W.Y.; Lawal, B.; Mokgautsi, N.; Huang, H.-S.; Ho, C.-L. HNC0014, a Multi-Targeted SmallMolecule, Inhibits Head and Neck Squamous Cell Carcinoma by Suppressing cMet/STAT3/CD44/PD-L1 Oncoimmune Signature and Eliciting Antitumor Immune Responses. Cancers (Basel) 2020, 12, 3759.

25. Lawal, B.; Liu, Y.-L.; Mokgautsi, N.; Khedkar, H.; Sumitra, M.R.; Wu, A.T.H.; Huang, H.-S.
Pharmacoinformatics and Preclinical Studies of NSC765690 and NSC765599, Potential STAT3/CDK2/4/6 Inhibitors with Antitumor Activities against $\mathrm{NCl} 60$ Human Tumor Cell Lines. Biomedicines 2021, 9, 92, doi:10.3390/biomedicines9010092.

26. Oshevire, D.B.; Mustapha, A.; Alozieuwa, B.U.; Badeggi, H.H.; Ismail, A.; Hassan, O.N.; Ugwunnaji, P.I.; Ibrahim, J.; Lawal, B.; Berinyu, E.B. In-silico investigation of curcumin drug-likeness, gene-targets and prognostic relevance of the targets in panels of human cancer cohorts.

27. Trott, O.; Olson, A.J. AutoDock Vina: improving the speed and accuracy of docking with a new scoring function, efficient optimization, and multithreading. J Comput Chem 2010, 31, 455-461, doi:10.1002/jcc.21334.

28. Mokgautsi, N.; Wang, Y.-C.; Lawal, B.; Khedkar, H.; Sumitra, M.R.; Wu, A.T.H.; Huang, H.-S. Network Pharmacological Analysis through a Bioinformatics Approach of Novel NSC765600 and NSC765691 Compounds as Potential Inhibitors of CCND1/CDK4/PLK1/CD44 in Cancer Types. Cancers (Basel) 2021, 13, 2523.

29. Visualizer, D.S. BIOVIA, Dassault Systèmes, BIOVIA Workbook, Release 2020; BIOVIA Pipeline Pilot, Release 2020, San Diego: Dassault Systèmes. 2020.

30. Arthur, D.E.; Uzairu, A. Molecular docking studies on the interaction of $\mathrm{NCl}$ anticancer analogues with human Phosphatidylinositol 4,5-bisphosphate 3-kinase catalytic subunit. Journal of King Saud University - Science 2019, 31, 1151-1166.

\section{Submit your article to AROC JOURNALS} -AROC in Pharmaceutical and Biotechnology -AROC in Agriculture -AROC in Food and Nutrition -AROC in Natural Product Research -BIOMED Natural and Applied Science Via https://arocjournal.com/ 